\title{
Avaliação da biblioteca escolar para o desenvolvimento de competências informacionais: a experiência da biblioteca do Instituto Federal da Bahia - Campus Camaçari
}

\author{
Evaluation of the school library for the development of information literacy: the experience of \\ the Instituto Federal da Bahia's library - Campus Camaçari
}

\author{
Andréia Santos Ribeiro Silva \\ Mestranda em Ciência da Informação da Universidade Federal da Bahia. \\ Bibliotecária do Instituto Federal da Bahia - Campus Camaçari \\ E-mail: asribeiro2001@gmail.com
}

Dulce Amélia Brito Neves

Doutora em Ciência da Informação pela UFMG. Docente do Programa de Pós Graduação em Ciência da informação da Universidade Federal da Paraíba - UFPB.

E-mail: damelia1@gmail.com

\author{
Maria Yêda F. S. de Filgueiras Gomes \\ Doutora em Ciência da informação e da Comunicação - École des Hautes Études em Sciences Sociales, França. \\ Docente do Programa de Pós Graduação em Ciência da informação - UFBA \\ E-mail: yedafgomes@ hotmail.com
}

\begin{abstract}
Resumo
Trata a biblioteca escolar como espaço de conhecimento, mediado pela figura do professor e do bibliotecário. $\mathrm{O}$ objetivo do estudo é investigar o perfil da comunidade acadêmica do Instituto Federal da Bahia - Campus Camaçari e quais são as suas necessidades de informações, com vistas para o desenvolvimento de competências informacionais. Apresenta a abordagem alternativa para o estudo de usuários que se preocupam com a necessidade e o uso da informação. Aborda que a biblioteca escolar deverá atender a demanda da educação para o novo milênio, desenvolvendo nos alunos as competências relacionadas às dimensões de habilidades (saberfazer); atitudes (saber-agir); e conhecimento (saber), tornando-se sujeitos autônomos. Para isso, traz o modelo de processo de busca da informação de Kuhlthau, necessário a todos os indivíduos na sociedade da Informação. A metodologia utilizada foi a de estudo de usuários com a aplicação de questionários eletrônicos, percebeu-se a necessidade de pesquisas futuras com usuários através da aplicação do protocolo verbal que diante da subjetividade nas respostas, torna-se mais próximo da validade. Conclui que a biblioteca escolar está deixando de ser um espaço estático e silencioso para torna-se um espaço de pesquisa e questionamentos.
\end{abstract}

Palavras-chave: Estudo de usuários. Biblioteca escolar. Competência em Informação. Protocolo Verbal.

\begin{abstract}
It considers the school library as a place of knowledge, mediated by the teacher and librarian's figures. The aim of this study is investigate the profile of the academic community of Instituto Federal da Bahia - Campus Camaçari and what are its information needs aiming at the development of information literacy. It presents an alternative approach to the study of users that cares about the use and need of information. Discusses that the school library shall meet the demand of education for the new millennium, developing in students the competences related to measurements of skills, attitudes and knowledge, becoming autonomous subjects. For this, it brings the model of Kuhlthau's information searching process, necessary for all individuals in the information society. The methodology used was the study of users with application of electronic questionnaires, it was realized the need for future research with users through the application of verbal protocol that given the subjectivity in the responses, it becomes closer to the validity. It concludes that the school library is no longer a static space and quiet to become a space of research and questions.
\end{abstract}

Keywords: Study of users. School library. Information literacy. Verbal protocol. 


\section{Introdução}

Muitos textos da área de Ciência da Informação, principalmente aqueles que tratam das questões de biblioteca, e neste caso particular a biblioteca escolar, refletem que as bibliotecas precisam ser o centro permanente de educação dentro do ambiente escolar. Mota (2006) assevera que a biblioteca, quando inserida no contexto escolar, tem como um de seus principais objetivos, auxiliar e facilitar o processo de ensino-aprendizagem. Não só auxiliar, mas também participar da vida acadêmica inserida no contexto cultural e de cidadania dos alunos.

Para isso é necessário que bibliotecários e professores sejam mediadores e trabalhem em cooperação, ofertando assim diversas atividades e serviços. Se o professor trabalhar determinado contexto em sala de aula e ao mesmo tempo a biblioteca refletir culturalmente o mesmo tema em uma exposição ou outra atividade que remetam os alunos as suas atividades acadêmicas, provavelmente, a escola fará com que esses alunos estabeleçam laços, proporcionando uma maior interação. A teoria construtivista diz que o conhecimento individual é um mapeamento de ações viáveis a sua experiência. Conforme Boiko e Zamberlan (2001) o papel do professor é caracterizado como o de mediador entre os significados pessoais dos seus alunos e os culturalmente estabelecidos, promovendo o aprendizado e o desenvolvimento dos mesmos. Dessa forma entendemos que o bibliotecário também pode ser o mediador das atividades que a biblioteca escolar deverá desenvolver em parcerias com o professor, desenvolvendo assim competências informacionais nos alunos.

O manifesto da UNESCO sobre a biblioteca escolar reafirma este pensamento quando diz que os bibliotecários e os professores, cooperando entre si, estimulam os alunos a alcançarem níveis mais altos de conhecimento, leitura, aprendizagem, solução de problemas e competências, no que diz respeito à utilização de tecnologias da informação e da comunicação (MOTA, 2006).

No pensamento de Carvalho Silva e Silva (2012, p. 21) a biblioteca escolar, na figura do bibliotecário em cooperação com o professor possui um mundo de interações em prol do aluno: 
naturais e energéticos de forma equilibrada), cultura popular (expressões da cultura local, regional e nacional) e também relativo a discussão sobre metodologias e práticas para as disciplinas escolares que possam estimular o pensamento crítico quando as práticas curriculares, como Português (redação, interpretação de textos...); História (questões relativas a história local, regional, nacional e global); Geografia (questões de espaço, geopolítica, nações, territórios, relação entre homem e natureza, etc.); Matemática (por exemplo, aprimoramento das metodologias para ensino e aprendizagem na disciplina de forma dinâmica, observando o pensamento de especialistas e possivelmente chamando algum especialista para diálogo); Ciências/Biologia (estudos sobre a natureza em suas diversas nuances animais, vegetais e minerais).

Dessa forma é que foi proposto o projeto de avaliação da biblioteca escolar do Instituto Federal da Bahia - Campus Camaçari, para investigar o perfil da comunidade acadêmica e quais as suas necessidades de informação, com vistas ao desenvolvimento de um programa de competência em informação. Após a obtenção dos dados pretende-se planejar atividades em cooperação com os professores de diversas áreas com o intuito de desenvolver nesses alunos as competências necessárias para a busca da informação, preparando os mesmos para trabalharem com autonomia.

\section{O Instituto Federal da Bahia: breve contextualização}

Com a publicação da Lei $n^{\circ} 11.892$, em 30 de dezembro de 2008, foram criados imediatamente os Institutos Federais de Educação, Ciência e Tecnologia em todo o país, deixando, por consequência, de existir os Centros Federais de Educação, Ciência e Tecnologia (CEFETs). Tendo como características e proposta de trabalho a oferta de educação formal, com vistas à educação profissional nos diversos setores da economia.

Conforme Becker e Chagas (2012) desde a sua criação, a cronologia da rede federal de educação foi composta por outras instituições. A Escola de Aprendizes e Artífices criada em 1909, pelo então presidente da República Nilo Peçanha, tinha o objetivo de profissionalizar filhos de famílias populares oferecendo assim a eles uma oportunidade de profissionalização para o mercado de trabalho. Sendo assim, a instituição oferecia como reforço alimentar para esses alunos o mingau como merenda escolar, com isso, logo passa a ser conhecida entre a população como a Escola do Mingau. Em 1942 em Salvador, a Escola de Aprendizes e Artífices passa à condição de Escola Técnica de Salvador, fazendo parte da rede federal de estabelecimentos de ensino industrial, e em 1965 por uma imposição legal, as Escolas Técnicas são transformadas em autarquias e o seu nome passa para Escola Técnica Federal da Bahia, com essa denominação a Escola Técnica vira referência no ensino profissionalizante 
pela proposta de ensino público com qualidade (FARTES e MOREIRA, 2009).

Com proposta de ampliação institucional, o ensino técnico de nível médio integra-se com o curso superior tecnológico, nascendo assim, em 1993, uma nova concepção de instituição que foi denominado de Centro Federal de Educação, Ciência e Tecnologia da Bahia, o CEFET-BA. Com a lei 11.892/2008 uma nova marca e mudança na educação profissional ocorreram em 2009. O Instituto Federal da Bahia (IFBA) surge juntamente com outros Institutos Federais em todo Brasil formando a Rede Federal de Educação. Com uma proposta de educação linear que não existe em nenhum outro país, oferecendo educação básica, superior e profissional em uma única instituição.

Diante dessa mudança institucional houve também uma mudança no paradigma das bibliotecas do Instituto Federal da Bahia. Hoje, para atender a essa nova demanda de usuários é necessário que as bibliotecas estejam padronizadas nos moldes das grandes instituições de ensino superior, já que o público que atende perpassa por todos os níveis que vai desde o curso de ensino médio, PROEJA, FIC (Formação inicial e continuada), Graduação e PósGraduação, além dos docentes e Técnico-administrativos.

O IFBA é uma instituição multicampi que conta hoje com 16 Campi em funcionamento, com mais cinco campi em implantação e perspectivas de novos campi, todos com bibliotecas. A Missão das bibliotecas em funcionamento ainda não é bem esclarecida, mas entendemos que é apoiar as atividades de ensino, pesquisa e extensão do IFBA, bem como atender as necessidades informacionais da comunidade interna e externa, promovendo o acesso à informação disponível nos variados suportes, visando atender com qualidade a demanda crescente dos serviços das bibliotecas.

\subsection{A biblioteca do campus Camaçari}

As bibliotecas do IFBA ainda seguem os padrões do antigo CEFET-Ba, onde elas pertenciam a uma unidade isolada sem formar uma rede ou um sistema de bibliotecas, atendendo especificamente ao público escolar. Hoje, como relata Becker e Chagas (2012) além do público escolar, as bibliotecas dos IFs também passam a atender alunos de ensino superior e público da educação de jovens e adultos. Sendo assim, as bibliotecas do IFBA vêm se reestruturando não só no sentido de atender esse novo público como também de transforma-se em um sistema integrado de bibliotecas. Para fins deste estudo escolhemos a 
biblioteca do IFBA Campus Camaçari que é um espaço destinado à disseminação do conhecimento para toda a comunidade acadêmica. Reunindo um acervo especializado nas áreas de Tecnologia da Informação e Eletrotécnica, contemplando ainda, áreas correlatas ao currículo escolar do ensino médio.

O principal objetivo da biblioteca do Campus Camaçari é organizar, controlar, conservar e disseminar o acervo bibliográfico. Visando o aprimoramento intelectual dos seus usuários, o desenvolvimento e o crescimento da instituição. Disponibilizando para isso o acervo bibliográfico através de consultas e empréstimos domiciliar. Contribuindo assim com o processo ensino-aprendizagem, como suporte às atividades pedagógicas.

A biblioteca foi implantada em março de 2008, em cinco anos de pleno funcionamento já passou por algumas transformações, dentre as quais foi a implantação de um software livre para dar uma melhor credibilidade aos serviços da biblioteca, o horário de atendimento ampliado em turnos ininterruptos, a compra de acervo passou a ser anual com verba específica.

E no ano de 2012, a biblioteca passou a fazer do Programa de Assistência ao Educando (PAAE) vinculado ao Projeto de Incentivo à Aprendizagem (PINA) recebendo duas bolsistas para a concretização do projeto - Biblioteca escolar: espaço de construção do conhecimento, cujo objetivo foi realizar um estudo no qual a biblioteca do Campus fosse avaliada pela comunidade, para com esses subsídios desenvolver um programa de Competência Informacional entre os alunos de ensino médio, atendendo a nova demanda da educação no novo milênio, que levam o indivíduo a aprender a aprende, e aprender ao longo da vida, um dos pilares da educação para o século XXI, que desenvolva nos alunos de ensino médio as competências necessárias relacionadas às dimensões de habilidade (saber-fazer); Atitudes (saber-agir) e conhecimentos (saber) tornarem-se autônomo. Para este trabalho foi proposto uma avaliação para conhecer o perfil e o interesse da comunidade com vistas à competência informacional. 


\section{Necessidades de Informação e a Competência em Informação}

A partir da década de 1940 após a explosão bibliográfica ocorrida com o uso das tecnologias digitais, iniciou-se, na área tradicional da Biblioteconomia, o processo de conhecimento do perfil dos usuários, os quais foram denominados de: Estudos de Usuários, Estudo das Necessidades de Informação ou Usos da informação. A evolução desses estudos é o que hoje denominamos de Comportamento informacional, difundido a partir da década de 1970. Estes estudos já vinham sendo realizados desde os princípios do século XX, mas igualmente tinham poucas preocupações com as necessidades que levavam as pessoas a usar a biblioteca como fonte de informação (WILSON, 1999).

Miranda (2006, p.100) assevera que Dervin e Nilan em 1986 concluíram que era necessária uma mudança nesse paradigma tradicional dos estudos de usuários para uma abordagem alternativa, detectando novos direcionamentos e tendências voltadas aos usuários da informação, como:

a) as necessidades dos usuários deveriam se tornar o foco central da operação de sistemas;

b) os serviços de informação deveriam ser ajustados às necessidades específicas do indivíduo, e não o contrário;

c) O foco deveria ser dirigido aos usuários ao invés dos sistemas de informação voltados as tecnologias e conteúdos, e por fim;

d) deveria ser colocado o foco nos próprios usuários.

O conceito de comportamento informacional inicialmente baseava-se em uma visão unidimensional, ora focada no comportamento do usuário, comportamentalista, ora focado no cognitivo do indivíduo e em outros momentos o foco estava no lado social.

Wilson (2000), define comportamento informacional como:

a totalidade do comportamento humano em relação às fontes e canais de informação, incluindo a busca passiva e ativa da informação e o uso da informação. Assim, inclui a comunicação face a face com os outros, assim como a recepção passiva de informação [...] sem intenção de agir sobre a informação dada.

Pettigrew, Fidel e Bruce (2001, p. 44, grifo nosso) trazem outra definição para o comportamento informacional como "o estudo de como as pessoas necessitam, buscam e atribuem significado à informação em diferentes contextos, incluindo no local de trabalho e na vida cotidiana". 
Os autores buscaram explicar as nuances do comportamento informacional com base na perspectiva multifacetada que inclui todos os aspectos contextuais do processo de busca e uso da informação. Percebe-se que o comportamento de usuários de informação não pode ser uma busca passiva, os usuários alunos, professores e servidores precisam interagir com as fontes de informação, saber utilizar os canais formais, tornar-se competente em informação. Miranda (2006) explica ainda que essa definição do comportamento informacional é considerada consistente com o que pode ser denominado: a totalidade do comportamento humano em relação a fontes e canais de informação.

No final da década de 1970 muitos teóricos como Dervin, Ellis, Kuhlthau e Wilson, conceberam uma abordagem alternativa aos estudos de usuários que se preocupavam com a necessidade e o uso da informação, a preocupação a partir deste momento passa a ser com uma abordagem centrada no indivíduo. A necessidade de uso da informação está relacionada a uma abordagem cognitiva, que segundo Ingwersen (1996),

na abordagem centrada no usuário a informação é entendida como resultado da
interpretação humana durante a interação com as fontes ou sistemas de informação
através de qualquer forma de mediação ou interface. Concentra-se além do
indivíduo, inclui, também, o impacto social dos processos comportamentais.

A literatura brasileira sobre o tema aborda questões que segundo Miranda (2006) traz a revisão dos paradigmas dos estudos de usuários realizados por Ferreira (1997) e Figueiredo (1983) que revisou os conceitos de necessidades (aquilo que o indivíduo necessita para o seu trabalho, pesquisa); demanda (o que o indivíduo pede); uso da informação (aquilo que o indivíduo realmente utilizou).

O comportamento informacional pode ser definido como a relação do indivíduo com as fontes e canais de informação, levando esse indivíduo a estabelecer processos mentais de entendimento e integração, colocando em pauta a perspectiva cognitiva do usuário.

Na sociedade da informação a educação requer um aprendizado continuo, ao longo da vida, requer ainda que o individuo tenha uma educação continuada, que lhe permita acompanhar as mudanças tecnológicas e, sobretudo inovar, criando competências requeridas pela nova economia. Para a nova sociedade, baseada no conhecimento e uso da informação e das tecnologias digitais, o aprendizado ao longo da vida e as habilidades informacionais começam a dar espaço a outro termo designado de Competências em Informação, que não se limita ao conhecimento do uso das fontes de informação e de bibliotecas, mas diz respeito, sobretudo, em entender, avaliar criticamente e usar o autoaprendizado e a tecnologia de forma 
ética.

A Competência em Informação constitui uma capacidade essencial aos cidadãos para se adaptarem à nova realidade da sociedade informacional. Implicando que as pessoas tenham capacidade de entender suas necessidades de informação e saber localizá-las, selecioná-las e interpretar essas informações, utilizando-as de forma crítica e responsável.

$\mathrm{Na}$ atual Sociedade da Informação uma das tarefas importantes da biblioteca escolar é proporcionar o uso de fontes de informação e transformação dessas informações em conhecimento, especialmente dos estudantes em fase de aprendizagem. Professores e bibliotecários precisam formar experiência para desenvolver a competência em informação no estudante.

\subsection{O processo de aprendizagem na biblioteca escolar}

Na chamada Sociedade da Informação, as escolas precisam preparar seus estudantes para um mundo voltado para a era tecnológica. Como assegura Kuhlthau (1999) "não se pode perder de vista que o mundo para o qual está se preparando o estudante é um mundo voltado para a tecnologia”. Sendo assim, a escola e a biblioteca da escola precisam preparar esse aluno para vivenciar suas experiências nesta Sociedade da Informação a qual produz um novo desafio na educação, aprender a aprender. A biblioteca precisa ofertar variadas fontes de informação e ensinar o aluno tornar-se autônomo na pesquisa escolar, assim o aluno terá independência e levará esse aprendizado para a sua vida cotidiana e profissional. A escola precisa preparar o aluno para que o mesmo possa ter responsabilidades básicas com o mercado de trabalho; com a cidadania e para a vida cotidiana.

O trabalhador precisa de um alto nível de competência e de habilidade para se
adaptar em ambientes em constante mutação. Em segundo lugar, na preparação do
estudante para a cidadania é necessário considerar as maneiras pelas quais a
tecnologia muda o senso de comunidade do individuo e suscita questões urgentes
sobre a sua forma de participação como eleitor informado em uma sociedade
democrática. Em terceiro lugar, na preparação de estudantes para a vida cotidiana
deve-se considerar as formas pelas quais a tecnologia aumenta a complexidade da
vida e desencadeia questões problemáticas sobre como o indivíduo alcança um
sentido de si mesmo em relação ao outro e desenvolve criatividade e satisfação
pessoal (KUHLTHAU, 1999, p. 9).

A mesma autora cita ainda a American Association Of school Librarians (AASL) que publicou padrões para as bibliotecas escolares onde os bibliotecários e os professores trabalham em conjunto, colaborando como o processo de ensino-aprendizagem gerenciando o 
programa destinado a desenvolver a competência em informação, tais como:

a) habilidade de aprender em situações dinâmicas, onde a informação está em constante mudança;

b) habilidade de gerenciar grandes quantidades de informação. Delimitando o volume de informações suficientes e possuindo habilidades para saber localizar e selecionar a informação relevante;

c) habilidade de encontrar significado através da produção de sentido em mensagens diversas e numerosas que geralmente não se acham organizadas previamente em textos, e;

d) habilidade de construir um entendimento próprio a partir de informações incompatíveis e inconsistentes.

Desse modo, a competência em informação habilita o aluno a construir seus próprios sentidos, possuindo habilidades de leitura, escrita e cálculo, se adaptando as tecnologias de informação e comunicação (TIC), pois ele precisa desenvolver habilidades que o ajude a aprender a partir de uma abundância de informações.

Para que este objetivo possa ser alcançado em uma biblioteca escolar e que a mesma possa construir sentidos na vida de um aluno, serão necessários uma reestrutura na aprendizagem baseada em questionamentos, "onde o estudante está envolvido ativamente no processo de construção de significados" (KUHLTHAU, 1999), nesse cenário o bibliotecário deverá desempenhar um papel importante na criação de uma biblioteca escolar como centro de questionamentos.

Pensando nesse sentido é que a bibliotecária norte-americana Kuhlthau (1991) pesquisou e desenvolveu o modelo Information Searching Process (ISP) que é uma abordagem alternativa ao modelo do comportamento informacional que descreve pessoas que procuram informação para realizar uma determinada tarefa dentro de um determinado período de tempo, como o caso da pesquisa escolar na biblioteca escolar. Segundo Campelo (2010) a aprendizagem nesse processo acontece pela construção ativa de novas ideias ligadas aos processos cognitivos de cada aluno. Para Kuhlthau (2010, p. 24) "a pesquisa que utiliza a abordagem baseada em processos combina a aprendizagem de conteúdos com a de habilidades de uso da informação, necessários para lidar com problemas reais em contextos do mundo real na era da informação".

Nesse sentido, a biblioteca escolar deve assegurar que o aluno tenha uma 
aprendizagem baseada em processos para a atividade da pesquisa escolar que deverá "estar centrada na construção do conhecimento do usuário" (CARVALHO SILVA e SILVA, 2012, p. 17).

Os mesmos autores, citando Pedro Demo (1996), consideram que a educação pela pesquisa ocorre em dois momentos: primeiro, quando o professor aplica a pesquisa no seu cotidiano e faz dela uso constante dessa atividade, servindo assim de exemplo para os seus alunos; e a segunda, quando o aluno apreende os passos da pesquisa e passa a ser companheiro de trabalho desse professor. Para isso, é necessário competências do professor, orientador da pesquisa escolar; do bibliotecário, responsável pelo ensinamento das fontes de informação e orientação para a pesquisa na biblioteca escolar; e do aluno, a quem se destina a educação pela pesquisa.

Segundo Carvalho Silva e Silva (2012, adaptado de Demo, 1996) para incentivar o hábito de pesquisa, a biblioteca da escola poderá mediar atividades que possam ser aplicadas, tais como: elaborar guias para a elaboração de artigos, projetos, monografias, normalização e outros; promover a divulgação permanente de eventos, revistas e produção dos docentes. Estimular a atividade de pesquisa como a produção do conhecimento; elaborar eventos, palestras, e outras atividades que abordem o cotidiano da comunidade.

Kuhlthau (2010, p.24) completa dizendo:

desenvolver habilidades de pesquisa como um processo de busca da informação. Sendo necessário para muitos indivíduos na Sociedade da Informação possuir a habilidade de identificar necessidades de informação, localizar informações apropriadas e utilizá-las para aprender, tomar decisões e resolver problemas é necessário a qualquer pessoa.

O modelo do processo de busca para a pesquisa ocorre em seis estágios (iniciação, seleção, exploração, formulação, coleta, apresentação) e deverá ser aplicado em uma biblioteca tanto escolar quanto em outras fases de aprendizagem. Os estágios do processo são denominados de acordo com a tarefa a ser realizada e os sentimentos que envolvem cada etapa. A avaliação ao final do processo torna-se necessária para examina o progresso que foi obtido pelo aluno. 
Processo de Busca da Informação

\begin{tabular}{|c|c|c|c|c|c|c|}
\hline $\begin{array}{l}\text { Estágios } \\
\text { Sentimentos } \\
\text { (afetivo) }\end{array}$ & $\begin{array}{l}\text { Iniciação } \\
\text { incerteza }\end{array}$ & $\begin{array}{l}\text { Seleção } \\
\text { otimismo }\end{array}$ & $\begin{array}{l}\text { Exploração } \\
\text { confusão } \\
\text { frustração } \\
\text { dúvida }\end{array}$ & $\begin{array}{l}\text { Formulação } \\
\text { clareza }\end{array}$ & $\begin{array}{l}\text { Coleta } \\
\text { senso de } \\
\text { direção/ } \\
\text { confiança }\end{array}$ & $\begin{array}{l}\text { Apresentação } \\
\text { satisfação ou } \\
\text { desapontamento }\end{array}$ \\
\hline \multirow{2}{*}{$\begin{array}{l}\text { Pensamentos } \\
\text { (cognitivo) }\end{array}$} & & & & $\longrightarrow$ focado & & \\
\hline & & & & & \multicolumn{2}{|c|}{ crescimento do interesse } \\
\hline $\begin{array}{l}\text { Ações } \\
\text { (físico) }\end{array}$ & \multicolumn{2}{|c|}{ buscando inf. relevante } & & & \multicolumn{2}{|c|}{ buscando inf. pertinente } \\
\hline
\end{tabular}

Fonte: Kuhlthau (2004, p. 82).

$\mathrm{Na}$ fase inicial do processo de busca, o aluno sente-se confuso e inseguro, pois ainda não possui domínio do conteúdo abordado para a pesquisa. Como assegura Campelo (2010), a biblioteca da escola nesta fase pode ser o espaço para o desenvolvimento dessa atividade e o bibliotecário da escola pode ser o parceiro nesse processo junto ao professor. Uma boa biblioteca possuindo coleções selecionadas que atenda ao perfil do seu público, sendo organizada de forma a permitir que o aluno encontre o material que procura pode também auxiliar o aluno no processo de busca da informação, fazendo com que durante a fase de seleção o aluno possa diminuir a sua incerteza e começar a se familiarizar com o que está pesquisando.

Possuindo um pouco de certeza e sensação de otimismo o estudante começa a fase de exploração dos materiais necessários à sua produção, nesta fase ele será capaz de coletar informações que o ajudem a formular o foco da sua pesquisa, mais uma vez uma biblioteca bem organizada, com profissional bibliotecário auxiliando o processo de busca da informação, poderá fazer com que esse aluno encontre o foco da sua pesquisa de forma mais rápida e com qualidade de busca. Nesse momento o estudante precisa ter conhecimento sobre a literatura daquilo que ele estabeleceu como foco para o seu trabalho. Em seguida o aluno percebe a sua perspectiva em relação ao que ele está pesquisando, tomando consciência de suas necessidades. Na fase da coleta o aluno deverá reunir todos os materiais que ele selecionou, fazendo conexões entre as informações e produzindo o texto que será apresentado para os seus colegas e professores.

O processo de produção do conhecimento é um meio adequado para levar os alunos a trabalhar com autonomia, usando variadas fontes de informação. Essa perspectiva esta centrada no processo de aprendizagem construtivista "que tem realizado estudos para ajudar a 
entender como as pessoas aprendem pela busca e uso de informações" (CAMPELO, 2010).

\begin{abstract}
Segundo este referencial, o conhecimento não é uma representação da realidade, mas um mapeamento das ações e operações conceituais que provaram ser viáveis na experiência do indivíduo. Portanto, a aprendizagem é um resultado adaptativo que tem natureza social, histórica e cultural. [...] o processo de desenvolvimento é otimizado pelo aprendizado e que a presença ou a colaboração de outra pessoa mais capaz conduz este processo, o referencial sócio construtivista situa a educação e a escola como tendo um papel essencial na promoção do desenvolvimento dos indivíduos, e o professor, como planejador, observador, promotor e desafiador do desenvolvimento dos mesmos. (BOIKO; ZAMBERLAN, 2001).
\end{abstract}

Pensando na possibilidade de ampliar os serviços oferecidos pela biblioteca do IFBA Campus Camaçari, além de conhecer o perfil do seu público e desenvolver atividades que estejam de acordo com esse perfil, trabalhando em conjunto com os docentes do Campus é que foi proposta a avaliação da biblioteca pelo usuário, através da interação de alunos do projeto PINA.

\title{
4. Resultados e Discussões
}

Para a presente pesquisa é necessário a escolha adequada de um método de pesquisa que neste trabalho ficou definido como um estudo de usuários, segundo Baptista e Cunha (2007) o estudo de usuários tem o objetivo coletar dados para avaliar produtos ou serviços informacionais. A técnica de pesquisa ocorreu por meio da aplicação de questionários eletrônicos planejados previamente e enviados exclusivamente pelo e-mail e facebook a todos os discentes, docentes e técnicos administrativos do IFBA - Campus Camaçari através do endereço <http://www.encuestafacil.com/RespWeb/Qn.aspx?EID=1424466>, o questionário foi desenvolvido pelas alunas bolsistas do projeto PINA, evitando assim que os bibliotecários da instituição formulassem questões que pudessem não refletir a realidade da biblioteca. Segundo Cunha (1982) questionário “é o método mais frequentemente utilizado para a coleta de dados em estudo de usuários. O questionário consiste numa lista de questões a serem propostas pelo pesquisador junto aos informantes para obtenção de dados, escolhidos pelos mais diversos métodos de amostragem." A avaliação ocorreu no período de 26 a 31 de janeiro de 2013, sendo prorrogada até o dia 06/02, por conta do baixo quantitativo de resposta na ocasião que também foi período de recesso para o carnaval, retomando as atividades logo após esse período as postagens do questionário on line foram encerradas.

Segundo Severino (2007) questionário é: 
conjunto de questões, sistematicamente articuladas, que se destinam a levantar informações escritas por parte dos sujeitos pesquisados, com vistas a conhecer a opinião dos mesmos sobre os assuntos em estudo. As questões devem ser pertinentes ao objeto e claramente formuladas, de modo a serem bem compreendidas pelos sujeitos.

A utilização de questionários em uma pesquisa é bastante controversa e polêmica a sua utilização como instrumento eficiente de pesquisa. Entretanto, é importante conhecer as vantagens e desvantagens da técnica abordada na visão de Cunha (1982).

Vantagens:

a) é um método rápido em termos de tempo, porque se estipula uma data para a devolução dos questionários preenchidos; b) é barato, porque o custo das tarifas postais para a remessa dos questionários é menor do que o custo de salários a serem pagos a entrevistadores; c) pode-se atingir, ao mesmo tempo, uma grande população dispersa numa ampla região geográfica; d) dá maior grau de liberdade e tempo ao respondente, pois o mesmo não é constrangido pela presença do entrevistador; e) há possibilidade de serem menores as distorções, desde que o informante não sofra a influência ou pressão do pesquisador.

\section{Desvantagens:}

a) pelo fato de o pesquisador estar à distância, dificulta para o respondente esclarecer dúvidas em relação a perguntas mal formuladas ou que contenham ambiguidade. Assim, não há oportunidade de responder às possíveis ambiguidades e de poder apreciar a validade das respostas dos informantes; b) as questões, por serem quase sempre formuladas por bibliotecários, nem sempre refletem os problemas enfrentados pelos usuários ou estão numa terminologia nem sempre a mais adequada ou de uso comum; c) o índice de resposta é quase sempre baixo, prejudicando enormemente a confiabilidade da amostragem. Por ser um método muito difundido é possível que os respondentes, por falta de tempo ou de motivação, deixem de responder e devolver o questionário; d) por ser um método rápido de coleta, é de praxe marcar uma data limite para devolução. Assim, muitos questionários deixam de ser computados na tabulação, quando são recebidos pelo pesquisador após a data indicada; e) é difícil saber se a resposta foi espontânea ou se sofreu a influência de outras pessoas; f) pelo fato de o respondente ter acesso a todas as perguntas, sem controle por parte do pesquisador, ele pode conhecer previamente todo o conteúdo do questionário, podendo assim afetar ou direcionar suas respostas.

Para divulgação à comunidade sobre o questionário as alunas do projeto PINA 
desenvolveram um cartaz para que todos pudessem antecipadamente saber que em breve a biblioteca da escola encaminharia um questionário que objetivasse conhecer a opinião de todos sobre a mesma.

Após a fase de divulgação foi encaminhado um link do questionário para o grupo do IFBA - Camaçari no Facebook, veículo comunicacional que é utilizado por alunos, professores e técnicos administrativos da instituição para divulgação de todos os eventos da escola. Nesse período foi constatado que alguns alunos, principalmente alunos da Licenciatura em Matemática e alunos do curso subsequente, pós-ensino médio, não faziam parte desse grupo, então foi tomada a decisão de encaminhar o link do questionário para alguns e-mails particulares, na tentativa de atingir um público maior aumentando assim a qualidade nas respostas.

Foram enviados 145 e-mails e alertas no grupo do facebook, tendo um total de 80 respondentes desse total, $54 \%$ dos respondentes se declaram do sexo feminino, refletindo assim a frequência da biblioteca pelas meninas dos cursos, e $74 \%$ dos respondentes foram os estudantes, também sendo o maior público frequentador da biblioteca escolar refletindo assim a frequência diária desse público que ficou em torno dos $45 \%$, enquanto aqueles que utilizam os serviços da biblioteca duas ou três vezes por semana ficou em $30 \%$, sendo que $50 \%$ dos entrevistados utilizam a biblioteca apenas para a realização do empréstimo e $21 \%$ para a leitura. Desse ponto de vista, podemos perceber que os alunos frequentadores da biblioteca da escola com idade aproximada de 16 anos ainda não pode perceber o potencial de uma biblioteca escolar como da mesma forma a biblioteca da escola ainda não conseguiu atingir esse público de forma eficaz, fazendo com que eles possam realizar outras atividades que o levem a competência em informação através dos processos de busca da informação. Quando perguntado sobre os serviços ofertados pela biblioteca que esse público conhece, não foi surpresa quando $47 \%$ dos respondentes declararam o empréstimo como serviço mais utilizado, seguido de $15 \%$ para o serviço de renovação, e quando perguntado sobre a sua satisfação quanto as suas necessidades informacionais 39\% consideraram médio o que encontram na biblioteca para atender as necessidades e outros 35\% declararam bom ou satisfatório as suas necessidades, percebemos assim que esse público ainda não conhecer as possibilidades de se realizar uma busca adequada da informação, ficando superficialmente nos conteúdos já trabalhos pelo professor, e a biblioteca da escola não tem desempenhado esse papel de mediador da informação para tornar esse público em questionadores. 
Apenas cinco respondentes se declararam professores da instituição refletindo a grande fragilidade desse público na biblioteca, dificultando também o contato com a equipe para realização de atividades que possam desenvolver a autonomia do aluno no processo de busca da informação já que a equipe da biblioteca não possui subsídios para saber o que acontece em sala de aula com os professores.

Quanto à infraestrutura do espaço da biblioteca destinado à leitura e outras atividades que levem esse aluno ao desenvolvimento de competências eles analisaram em $50 \%$ que as condições do ambiente são boas, $31 \%$ declararam que as condições dos equipamentos de informática para o uso dos alunos em geral é médio, solicitando assim a troca ou melhorias dos mesmos. A limpeza do ambiente e o mobiliário foram considerados como ótimo e bom pelos respondentes, percebemos então que o que mais chama a atenção por esses frequentadores são as tecnologias de informação para a realização de suas atividades e o empréstimo para estudos em casa. Dessa forma, não existe um elo entre o aluno e a biblioteca, eles utilizam o espaço apara realizar tarefas, conversas sobre diversos itens e por outro lado a biblioteca da escola também não atingiu esse público frequentador nas suas solicitações, para que esse público possa olhar o espaço de leitura, estudo e lazer com mais propriedade das funções de uma biblioteca escolar.

Dentre as solicitações dos respondentes dos questionários destacamos as atividades que sugeridas para integrar biblioteca e comunidade:

- Clube do Livro (cinco sugestões)

- Jogos Interativos (três sugestões)

- Sorteio de Livro (quatro sugestões)

- Aumento do Acervo de Livros (duas sugestões)

- Atividades dinâmicas de incentivo á leitura (três sugestões)

- Debates (uma sugestão)

- Post de Poesias (uma sugestão)

- Concurso de redação (duas sugestões)

- Café científico (uma sugestão)

- Gincana (uma sugestão)

- Sarau/Oficina de Poesias (três sugestões)

- Leitura em Grupo (uma sugestão)

- Concurso de Desenho (uma sugestão) 
- Oficina de Pesquisa (duas sugestões)

- Divulgação de documentários nacionais (uma sugestão)

- Espaço de descanso (uma sugestão)

- SEM RESPOSTA (duas sugestões)

Nesse período a biblioteca do Campus Camaçari realizou o primeiro concurso de desenho com parceria entre a biblioteca e a coordenação de linguagem, pois os temas a serem desenhados diziam respeitos a cada tema literário realizado pelas professoras de Língua Portuguesa nas turmas e série de cada aluno inscrito no concurso. A divulgação ocorreu entre os alunos de ensino médio, já que se trata do maior público que frequenta a biblioteca, precisando assim de uma maior integração também. O concurso teve como premiação a coleção de livros do Harry Potter e do Percy Jackson e os Olimpianos, uma literatura que foi solicitada por eles. Os desenhos foram expostos na sala de leitura da biblioteca e os professores de desenho, Língua Portuguesa e servidores da biblioteca votaram escolhendo assim o vencedor do concurso. Realizando assim a parceria biblioteca e docentes, para atender as necessidades de informação dos alunos. Outras atividades como o clube do livro já está sendo organizado pelas alunas do projeto PINA para que no final do projeto a biblioteca realize o clube do livro, uma solicitação que partiu dos estudantes.

Outras sugestões dos respondentes do questionário estão sendo providenciadas para que esses alunos possam perceber que a biblioteca da escola quer interagir com eles e dar um retorno educacional voltado para as competências individuais de cada um. Além de procurar se conectar com as novas ferramentas consideradas como eficazes para a comunicação entre os usuários e a biblioteca, tais como:

- E-mail

- Jornal

- Mural

- Guia do Usuário

- Redes Sociais

Sugestões encaminhadas como: comprar novos exemplares; incentivar a leitura através de projetos; aumentar o prazo de empréstimos; aumentar a quantidades de livros a serem emprestados; abrir a biblioteca mais cedo pela manhã; melhorar os computadores de acesso aos alunos além de liberar alguns sites não permitidos pela Coordenação de TI, essas foram algumas indagações de usuários que acreditam que desse modo a biblioteca do IFBA Campus 
Camaçari poderá tornar-se um espaço mais criativo e agradável para eles, permitindo que os mesmos possam tornar-se independentes no processo de busca da informação.

\title{
4.1 Possibilidades de pesquisas futuras
}

O estudo de usuário da informação em uma biblioteca precisa voltar-se para uma abordagem centrada no usuário e suas concepções cognitivas. Conforme Borges (2005) o estudo sobre as necessidades de informação de usuários de bibliotecas investigam o modo como esses usuários buscam a informação que necessitam, e como eles a utilizam para resolver suas questões de informação, transformando-a em conhecimento.

\begin{abstract}
Nesses estudos, encontram-se subjacente os princípios das abordagens tradicionais sobre a cognição humana, nas quais o individuo (usuário) é um ser que recebe informação do meio externo que lhe modifica as estruturas próprias de conhecimento. A informação, tomada como algo objetivo, e recebida pelo usuário, permite-lhe resolver gaps de conhecimento sobre algo. Além disso, esses estudos consideram a informação como algo que pode ser estocado, processado e transmitido e o conhecimento como algo que é obtido para resolver um problema relacionado a uma ausência de conhecimento sobre algo. (BORGES, 2005, p.78).
\end{abstract}

Percebe-se a necessidade de que estudos de usuários tenham uma abordagem cognitiva, centrada no usuário como seres únicos em um meio social, que transitam em diferentes relações, que influenciam as suas condutas, a sua linguagem e as suas prédisposições em aceitarem ou não determinadas informações (BORGES, 2005). Sendo assim, as pesquisas de abordagens qualitativas, que se baseiam no modo subjetivo da informação, para ser precisar em sua subjetividade precisam de uma técnica de coleta de dados que se aproxime dos dados válidos. Essa técnica pode ser os Protocolos Verbais, "também chamados de protocolos de pensar alto, usados para fazer referencias a verbalizações do pensamento, feitas por determinados indivíduos, durante o processamento de uma tarefa cognitiva" (BORGES, 2005, p. 152).

Neves (2001) considera que para a aquisição de conhecimento nossa mente trabalha com processos metacognitivos que funciona como elemento dinâmico de nossas atividades. Para a mesma autora os nossos fazeres diários utilizam-se de informações armazenadas na memória e composta por operações efetuadas pelo cérebro, que retém e recupera a memória quando necessário, sendo a base para o protocolo verbal.

A cognição humana apresenta-se como uma reprodução de conhecimentos estocados na memória, acompanhados das interpretações que lhe são associadas e das formas de processamento de informações, como, por exemplo, o processamento textual (NEVES, 2011, p. 45). 
Para Fujita e Cervantes (2005, p. 40) o Protocolo Verbal possui vantagens sobre outros tipos de técnicas de coleta de dados para estudo de usuários, como questionários ou entrevistas, porque segundo as autoras o protocolo verbal:

É a única que fornece acesso direto ao processo mental de leitura enquanto está sendo realizado pelo leitor, diferente das outras que revelam apenas a reflexão após o processo de leitura. Dessa forma, a técnica de 'pensar alto' é a única técnica propriamente introspectiva enquanto as outras são de natureza retrospectiva.

Os responsáveis pela sistematização dos Protocolos Verbais foram Ericson e Simon, que segundo Baldo (2011) tem o foco em instruir sujeitos a verbalizarem seus pensamentos, para assim buscarmos entender os traços indiretos dos processos cognitivos do individuo.

Os Protocolos Verbais apresentam também uma desvantagem em relação a outras técnicas de coleta de dados, a transformação do processo cognitivo em dado mensurável pela inferência do pesquisador, estando sujeito a interpretações equivocadas. Baldo (2011) diz que entre as vantagens de usarmos o método de coleta de dados do Protocolo Verbal é porque os sujeitos relatam comportamentos, uma vez que não há intervalos de tempo entre as leituras e as respostas.

O protocolo verbal usado como técnica de coleta de dados em pesquisas presenciais com usuários, onde eles possam verbalizar os seus pensamentos no momento da pesquisa, poderá refletir o que eles esperam da atuação da biblioteca na escola. Desse modo a aproximação com o usuário seria maior e os serviços se adequariam as reais necessidades deles.

Neves (2006) assevera que a técnica do protocolo verbal usada como procedimento metodológico oferece informações qualitativas que possibilita a obtenção de relatos individuais da própria cognição durante a execução de uma tarefa. A técnica poderá ser utilizada tanto para a leitura como em qualquer processo de aprendizagem que evidencie processos cognitivos. 


\section{Considerações finais}

As bibliotecas escolares estão deixando de ser um espaço estático, silencioso, destinado apenas a leituras silenciosas, essas bibliotecas estão se tornando um espaço para questionamentos e construção de saberes. A UNESCO diz que uma das funções básicas da biblioteca escolar está em proporcionar aos alunos competências para o aprendizado ao longo da vida e contribuir para o desenvolvimento de sua imaginação, permitindo que os mesmos adotem posturas e condutas de cidadãos responsáveis (MOTA, 2006).

Carvalho Silva e Silva (2012, p.21) destacam ainda que:

é pertinente que a escola possa abrir um espaço mais amplo para a biblioteca, visando inseri-la como espaço de prática pedagógica e inseri-la de forma cotidiana nas ações curriculares, disciplinares e cotidianas da escola. Desse modo, é possível aproximar o diálogo entre biblioteca e usuário discente de forma mais eficiente e eficaz. Entendemos que além das atividades pedagógicas da biblioteca consideradas mais convencionais que podem estimular a leitura e a pesquisa por meio do lúdico, como contação de histórias, teatro, música, dança, etc. é pertinente que a biblioteca desenvolva um conjunto de atividades que estimulem a prática da pesquisa como serviços de alerta informais (exposições, palestras, cursos) e formais (listas de novas aquisições) e ainda, assim como foi sugerido aos professores com relação às disciplinas a biblioteca também pode fazer com os usuários discentes.

Observamos que é necessário que a biblioteca do IFBA - Campus Camaçari repense as suas atividades enquanto promotora de aprendizagem, realizando atividades em parcerias com docentes que assegurem no discente as competências necessárias para que o mesmo possa aprender a aprender na Sociedade da Informação.

\section{Referências}

BALDO, A. Protocolos verbais como recurso metodológico: evidencia de pesquisa. Horizontes de Linguística aplicada, ano 1, n. 1, jan./jun. 2011.

BAPTISTA, S. G.; CUNHA, M. B. Estudo de usuários: visão global dos métodos de coletas de dados. Perspectivas em Ciência da Informação, Belo Horizonte, v. 12, n. 2, p.168-184, maio/ago. 2007.

BECKER, C. R. F.; CHAGAS, M. As bibliotecas dos Institutos Federais de educação, ciência e Tecnologia - IFs: de escolares à também universitárias: a necessidade da reestruturação. In: SEMINÁRIO NACIONAL DE BIBLIOTECAS UNIVERSITÁRIAS, 22, 2012, Gramado/RS. Anais eletrônicos... Gramado: UFRGS, 2012. p. 1-9.

BOIKO, V. A. T. A; ZAMBERLAN, M. A. T. Perspectiva sócio construtivista na psicologia e na educação: o brincar na pré-escola. Psicologia em Estudo, Maringá, v. 6, n. 1, p. 51-58, 
jan./jun. 2001.

BORGES, M. E. N. A abordagem contemporânea sobre a cognição humana e as atribuições para os estudos de usuários da informação. Cadernos BAD, v. 2, 2005.

CAMPELO, B. O bibliotecário e a pesquisa escolar. Presença pedagógica, v. 16, n. 93, maio/jun. 2010.

CARVALHO SILVA, J. L.; SILVA, A. S. R. A mediação da informação como prática pedagógica no contexto da biblioteca escolar: algumas considerações. Biblioteca Escolar em Revista, Ribeirão Preto, v. 1, n. 2, p. 1-30, 2012.

CUNHA, M. B. da. Metodologias para estudo dos usuários de informação científica e tecnológica. R. Bibliotecon., Brasília, v.10, n.2, p. 5-19, jul./dez., 1982.

DEMO, P. Educar pela pesquisa. São Paulo: Autores Associados, 1996.

DERVIN, B. ; NILAN, M. Information needs and uses. Annual Review of Information Science and Technology. v. 21, p. 3-33, 1996.

FERREIRA, S. M. Estudo de necessidades de informação: dos paradigmas tradicionais à abordagem sense-making. ABEDB, n. 2, 1997.

FIGUEIREDO, N. M. Aspectos especiais de estudos de usuários. Ciência da Informação, Brasília, v. 12, n. 2, p. 43-57, jul./dez. 1983.

FUJITA, M. S. L.; CERVANTES, B. M. N. Abordagem cognitiva do protocolo verbal na confirmação de termos para a construção de linguagem documentária em inteligência competitiva. In: VALENTIM, M. L. (Org.). Métodos qualitativos em pesquisa em Ciência da informação. São Paulo: Polis, 2005. p. 29 - 58.

INGWERSEN, P. Cognitive perspectives of information retrieval. Journal of Documentation, London, v. 52, n. 1, p. 3-50, 1996.

KUHLTHAU, C. C. O papel da biblioteca escolar no processo de aprendizagem. In: VIANNA, M. M.; CAMPELO, B.; MOURA, V. H. V. Biblioteca escolar: espaço de ação pedagógica. Belo Horizonte: EB/UFMG, 1999. p. 9-14.

Seeking meaning: A process approach to library and information services. 2D ed. Libraries Unlimited. Westport, CT: 2004.

Inside the search process: information seeking from the user'sperspective. Journal of the American Society for Information Science, v. 42, n. 5, p. 361-371, 1991.

MIRANDA, S. Como as necessidades de informação podem se relacionar com as competências informacionais. Ciência da Informação, Brasília, v. 35, n. 3, p. 99-114, set./dez. 2006.

MOTA, F. R. L. Competência informacional e necessidade de interação entre bibliotecários e professores no contexto escolar. Informação \& Sociedade: Estudos, João Pessoa, v. 16, n. 1, 
p. 121-127, jan./jun. 2006.

NEVES, D. A. B. Metacognição, informação e conhecimento: pensando em como pensar. Recife: Néctar, 2011.

La verbalización como registro para análisis en la investigación sobre lectura. Anales de documentación, revista de Biblioteconomía y Documentación, Murcia, v. 9, 2006.

Disponível em: <http://www.um.es/fccd/anales/ad09/ad0900.html>. Acesso em: 17 jan. 2013.

PETTIGREW, K. E.; FIDEL, R.; BRUCE, H. Conceptual frameworks in information behavior. Annual Review of Infrmation Science and Technology, v. 35, p. 43-78, 2001.

SEVERIANO, A. J. Metodologia do trabalho científico. São Paulo: Cortez, 2007. 304 p.

WILSON, T. D. Human information behaviour. Informing Science, v. 3, n. 2, p. 49-52, 2000.

Models in information behaviour research. Journal of Documentation, London, v. 55, n. 3, p. 249-270, June, 1999. 